\title{
Secondary prevention and treatment of cervical cancer - an update from Poland
}

\author{
Patryk Poniewierza', Marcin Śniadecki², Michał Brzeziński², \\ Dagmara Klasa-Mazurkiewicz², Grzegorz Panek ${ }^{3}$
}

'Department of Biology and Medical Genetics, Medical University of Gdansk, Gdansk, Poland ${ }^{2}$ Department of Gynecology, Gynecologic Oncology and Gynecologic Endocrinology, Medical University of Gdansk, Gdansk, Poland ${ }^{3}$ Department of Oncologic Gynecology and Obstetrics, The Center of Postgraduate Medical Education, Warsaw, Poland

Introduction. Cervical cancer is the $4^{\text {th }}$ most common cancer in terms of incidence and mortality in women worldwide. The aim of the study was to investigate and analyze the effects of Poland's publicly funded cervical cancer screening and treatment programs.

Material and methods. The study analyzed the financial and epidemiological data provided by the Polish National Health Fund and the Polish National Cancer Registry on the prevention and treatment of cervical cancer in Poland in 2011-2017. Results. Our study identified a systematic reduction in the number of patients undergoing cervical cytology. Despite high levels of financial expenditure, no correlation was found between the total cost of benefits in PLN million (W=0.911; $p=0.404)$ and mortality expressed by the standardized coefficient ( $W=0.884 ; p=0.243$ ).

Conclusions. Despite decreasing mortality rates in cases of cervical cancer in Poland, the organization and delivery of prevention and treatment programs should be considered insufficient.

Key words: cervical cancer, screening, treatment, public health

\section{Introduction}

Cervical cancer (CC) is the fourth most common cause of morbidity and mortality among women worldwide. Worldwide, in 2020, incidence and mortality were 604,000 and 342,000, respectively [1]. In Poland in 2018, there were 2360 new cases, representing a world age-standardized rate (ASW) of 7.1 per 100,000 women annually, making it the $8^{\text {th }}$ most common cancer in the female population. The mortality figure was 1593 women, representing an ASW of 4.0 per 100,000. It is worth noting that the mortality rate for CC has recently been decreasing [2].

The Polish cervical screening program consists of a Pap smear (slide cytology) taken every 3 years. When lesions are detected, referred to as either atypical squamous cells of undefined significance (ASCUS) or low-grade squamous intraepithelial lesions (LSIL), a cytologic evaluation is repeated. A colposcopy with the possibility of a biopsy is performed for the following results: atypical squamous cells, cannot exclude a high-grade lesion (ASCH); high-grade squamous intraepithelial lesions (HSIL); atypical glandular cells (AGH); and in some cases, LSIL. Polymerase chain reaction (PCR) testing for the presence of HPV is not included in the program [3].

In Poland, reduced mortality is due to the introduction of secondary prophylaxis in the 1980s based on Pap smear testing (cervical cytology). In 2006, cervical screening beca-

\section{How to cite:}

Poniewierza P, Śniadecki M, Brzeziński M, Klasa-Mazurkiewicz D, Panek G. Secondary prevention and treatment of cervical cancer - an update from Poland. NOWOTWORY J Oncol 2022; 72: 20-25.

This article is available in open access under Creative Common Attribution-Non-Commercial-No Derivatives 4.0 International (CC BY-NC-ND 4.0) license, allowing to download articles and share them with others as long as they credit the authors and the publisher, but without permission to change them in any way or use them commercially. 
me a national program. The program involves regular Pap smears repeated at three-yearly intervals in women aged 25 to 59 . Until 2015, the administration of the screening program included sending personal invitation letters to women [4]. Following screening, the program's diagnostic and therapeutic steps include a colposcopy with cervical biopsy, surgical intervention (conization, hysterectomy), chemotherapy, and radiotherapy [5].

Despite a steady decrease in CC mortality, it is alarming that Poland's 5-year survival rate is the lowest (56.4\%) of all European countries where the European average is $62.4 \%[6,7]$.

Cervical cancer is an important health and economic issue. Prophylaxis against CC and the treatment of patients with CC are considerable burdens on public health funding. We believe that a systematic evaluation of the effect of screening programs can lead to the improved organization of resources. The aim of the study was to investigate and analyze the costs of Poland's publicly funded CC screening program and treatment for the period of 2011 to 2017, considering the latest data from CC statistics. The intention of the authors is that the results of the data analyses, regardless of the final conclusions, will be useful for future CC screening planning.

\section{Material and methods}

Our study used data on the screening program carried out in specialist outpatient clinics (ambulatoryjna opieka specjalistyczna - AOS [in Polish]), and CC treatments undertaken in public hospitals in Poland between 2011 and 2017, shared by the Polish National Health Fund (NHF) at the authors' inquiry. The NHF is the primary funder of the Polish healthcare system, and thus it collects extensive data on patient demographics, the number and type of services provided, costs generated, and the duration of hospital stays. In addition, we used epidemiological data on CC mortality rates published by the Polish National Cancer Registry (http://onkologia.org.pl). Among the screening data up to 2015 is a group of women obtained from sending personalized invitations. Treatment data is a separate statistic. It is not limited to the cases screened in 2011-2017.

We analyzed the results of all cervical cytology tests conducted in specialist outpatient clinics in the public healthcare system between 2011 and 2017, including the number of women tested, the percentage of the general population included in the program, the cost of the services provided, and the standardized mortality rate due to CC. We considered each case qualified for further in-depth diagnosis and / or treatment as an abnormal Pap test result (ASCUS, ASCH, LSIL, AGH or HSIL). Similarly, we evaluated the treatment of CC patients in Poland, without analyzing the proportion of the general population. Patients receiving medical services encoded with the C53 (malignant neoplasm of cervix uteri) code according to the ICD-10 classification were enrolled in the study in the treatment analysis.

To test for normality of distribution, we used the Shapiro-Wilk test. The direction and strength of linear correlations between two variables were evaluated using the Pearson correlation coefficient, and the t-test was used to evaluate the statistical significance of correlations. The significance level was set at $a=0.05$. We conducted our analysis using the R statistical program (v4.01).

\section{Results \\ Cervical cancer screening}

The data on cytological screening between 2011 and 2017 is shown in table I. In 2011, 793,400 women underwent screening in outpatient settings (AOS). Over subsequent years, the numbers decreased. By 2017, 463,000 women presented for screening, 41.6\% fewer than in 2011. A similar trend was observed in the annual percentages of the general population included in the screening program. The rate of abnormal screening test results requiring further diagnostic procedures was found to correlate significantly with the percentage of patients included in screening in the general population $(r=0.961 ; p=0.019)$.

Table I. Cervical cytology studies between 2011 and 2017

\begin{tabular}{|lcccccccc}
\hline Criterion & $\mathbf{2 0 1 1}$ & $\mathbf{2 0 1 2}$ & $\mathbf{2 0 1 3}$ & $\mathbf{2 0 1 4}$ & $\mathbf{2 0 1 5}$ & $\mathbf{2 0 1 6}$ & $\mathbf{2 0 1 7}$ & $\mathbf{2 0 1 7 / 2 0 1 1}$ (\%) \\
\hline $\begin{array}{l}\text { number of patients tested in } \\
\text { outpatient specialty care (AOS) }\end{array}$ & 793,398 & 726,548 & 665,520 & 691,682 & 652,258 & 538,273 & 462,970 \\
\hline $\begin{array}{l}\text { cost of procedures } \\
\text { (million PLN) }\end{array}$ & 40.15 & 39.49 & 36.03 & 28.50 & 27.07 & 22.69 & 20.21 \\
\hline $\begin{array}{l}\text { \% of general population } \\
\text { mortality rate-ASW }\end{array}$ & 24.4 & 23.75 & 22.91 & 22.34 & 21.72 & 20.5 & 18.73 \\
\hline
\end{tabular}

Table II. The number of patients having cervical cytology positive test result and the costs of detecting single positive case (qualified for further in-depth diagnosis and /or treatment) between 2014 and 2017

\begin{tabular}{lcccc}
\hline Criterion & $\mathbf{2 0 1 4}$ & $\mathbf{2 0 1 5}$ & $\mathbf{2 0 1 6}$ & $\mathbf{2 0 1 7}$ \\
\hline $\begin{array}{l}\text { number of patients with } \\
\text { positive test results }\end{array}$ & 19,940 & 18,521 & $\mathbf{2 0 1 7 / 2 0 1 4}(\mathbf{\%})$ & $\mathbf{1 3 , 7 0 7 5}$ \\
$\begin{array}{l}\text { costs of detecting a single } \\
\text { positive case (PLN) }\end{array}$ & 1429.50 & 1461.79 & 1505.16 & 1475.05 \\
\end{tabular}


Table III. Costs of cervical cancer treatment between 2011 and 2017

\begin{tabular}{|c|c|c|c|c|c|c|c|c|}
\hline Criterion & 2011 & 2012 & 2013 & 2014 & 2015 & 2016 & 2017 & $2017 / 2011(\%)$ \\
\hline number of patients & 22,478 & 22,829 & 22,850 & 22,377 & 21,730 & 21,113 & 20,511 & 91.2 \\
\hline $\begin{array}{l}\text { total costs of procedures } \\
\text { (million PLN) }\end{array}$ & 130.85 & 137.51 & 140.05 & 140.05 & 122.91 & 123.64 & 130.89 & 100.0 \\
\hline $\begin{array}{l}\text { average cost of treatment of } \\
\text { a single patient (PLN) }\end{array}$ & 5821.33 & 6023.67 & 6128.96 & 6258.63 & 5656.35 & 5855.96 & 6381.57 & 109.6 \\
\hline $\begin{array}{l}\text { total cost of surgery (million } \\
\text { PLN) }\end{array}$ & 14.32 & 15.07 & 14.86 & 13.76 & 14.08 & 12.91 & 13.02 & 90.9 \\
\hline $\begin{array}{l}\text { total cost of radiotherapy } \\
\text { (million PLN) }\end{array}$ & 56.70 & 63.24 & 65.34 & 66.74 & 58.79 & 60.42 & 61.61 & 108.7 \\
\hline $\begin{array}{l}\text { total cost of chemotherapy } \\
\text { (million PLN) }\end{array}$ & 25.83 & 26.63 & 26.18 & 27.46 & 25.23 & 24.95 & 23.40 & 90.6 \\
\hline
\end{tabular}

The number of patients with abnormal screening test results and the costs of detecting a single positive case (qualified for further in-depth diagnosis and / or treatment) in the years 2014-2017 are presented in table II. The data of the NHF register do not contain information from the previous years. In 2014, the number of abnormal cytology tests results reached nearly 20,000. In the following years, this number decreased. In 2017, there were 13,700 abnormal tests, which was 31.3\% fewer than in 2014. The cost of detecting one case over that period was similar to previous periods with mean cost $M=1467.86$ PLN (SD = 31.37 PLN). Despite fewer women presenting for screening and fewer abnormalities requiring further in-depth diagnosis and / or treatment being detected, there was a systematic decline in the age-standardized mortality rate (ASW) for CC, from 4.84\% in 2011 to $4.2 \%$ in 2017 (a decrease of 0.64 percentage points).

\section{Cervical cancer treatment}

The costs of treatment of patients with CC between 2011 and 2017, with respect to different types of treatment, are summarized in table III. Between 2011 and 2017, the overall cost of CC treatment was relatively constant, with the average per year cost being 132.3 million PLN (SD = 7.24 million PLN). Relatively minor differences were observed year-by-year with respect to the cost per patient, and also with respect to the costs of different treatment modalities (fig. 1). Despite the average annual cost of treatment (132 million PLN during the analy-

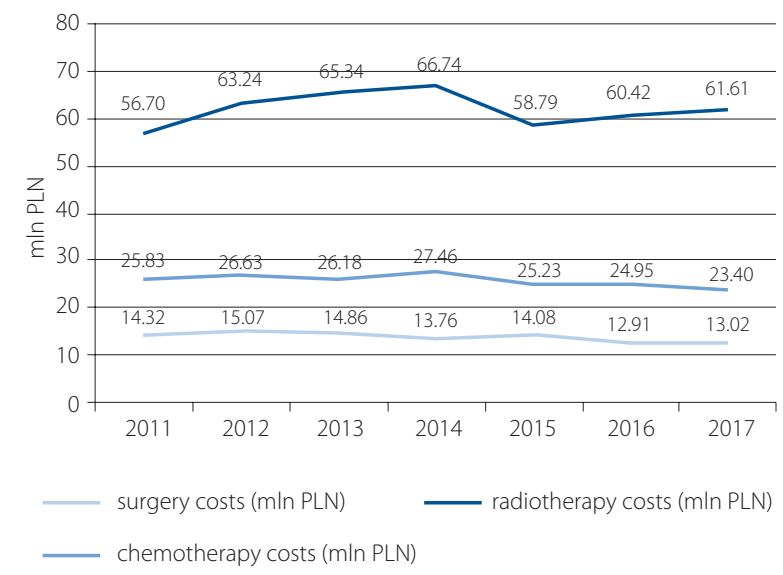

Figure 1. Costs of cervical cancer treatment divided by treatment modalities

zed period), no statistically significant correlation has been observed between the overall cost ( $W=0.911 ; p=0.404)$ and mortality expressed as the standardized coefficient ( $W=0.884$; $p=0.243$ ). Also, the correlation between the treatment costs per patient $(W=0.975 ; p=0.929)$ and mortality rates was not significant (tab. IV). The above-listed correlations showed no statistical significance even though there was an increased number of cytology study results and an increased number of services provided ( $r=0.886 ; p=0.008$ ). For a complete evaluation of hospital treatments over the studied period, we

Table IV. Correlation between total cost of procedures and cost of treating one patient with respect to mortality rate

\begin{tabular}{|c|c|c|c|c|}
\hline \multirow[t]{2}{*}{ Costs } & \multicolumn{4}{|c|}{ Mortality rate - ASW } \\
\hline & $\mathbf{N}$ & $r$ & $\mathrm{Cl}$ & $p$ \\
\hline cost of procedures (million PLN) & 7 & 0.641 & {$[-0.22-0.94]$} & 0.121 \\
\hline cost of treating one patient (PLN) & 7 & 0.008 & {$[-0.75-0.76]$} & 0.986 \\
\hline
\end{tabular}

Table V. Mean and maximum hospital stay between 2014 and 2017

\begin{tabular}{|lccccc}
\hline Criterion & $\mathbf{2 0 1 4}$ & $\mathbf{2 0 1 5}$ & $\mathbf{2 0 1 6}$ & $\mathbf{2 0 1 7}$ & $\mathbf{2 0 1 7 / 2 0 1 4 ( \% )}$ \\
\hline mean hospital stay (days) & 4.73 & 4.55 & 4.49 & 4.38 & 92.6 \\
\hline maximum hospital stay (days) & 104.38 & 95.88 & 101.38 & 96.56 & 92.5 \\
\hline
\end{tabular}


used both mean and maximum durations of the hospital stays (tab. V). In 2014, the mean hospital stay was 4.73 days. Over the following years, this index consistently decreased, reaching 4.38 days of hospital stay in 2017. The maximum hospital stay in 2014 was 104.38 days. Over the following years, this parameter's value also declined, reaching 96.56 days in 2017.

\section{Discussion}

Cervical cancer is the fourth most common cause of morbidity and mortality among women worldwide. However, its prevalence is inversely proportional to a country's medical resources, with incidence rates being highest in those countries where no cytology screening program is available at all [8]. Cervical cancer has been the focus of public health programs in Poland for the past 15 years. The result of this is that in the last three years alone, approximately $72 \%$ of women have undergone cervical cytology, according to the Organization for Economic Co-operation and Development (OECD) data [9]. Notwithstanding these and other countries' efforts, and despite the possibility of primary prophylaxis by vaccination against the human papillomavirus (HPV), it is expected that in the next 15 years, cases of CC worldwide will increase by $42 \%$ annually on average, while an $11 \%$ increase is expected in developed economies [10]. Poland's recent promotion to the rank of developed country in terms of capital markets does not correlate with its health ranking. One area where this lack of correlation is revealed is in the health outcomes resulting from cervical cancer screening tests.

Our study found a decline in the number and proportion of women enrolled in the national screening program in AOS over the 2011 to 2017 observation period. This is a negative connotation since the number of lesions requiring further diagnostics detected in cervical cytology correlates strongly with numbers of patients tested in outpatient specialty care (AOS) and the percentage of the national population covered by the screening program. In addition, Turkot et al., in their 2018 audit of cytology laboratories in Poland, found there was a significant increase in Pap testing outside the national healthcare program, that is, in the private healthcare sector [11]. Both our results and those of the authors mentioned above may suggest that Pap smear tests are performed in private healthcare. There is an open question about the reasons for the decline in patients' interest in examinations financed by the national screening program. The cessation of sending personalized invitations in 2015 can be considered to be one of the reasons. This action was dictated by low cost-effectiveness considerations [3]. The significantly positive correlation shown between the number of patients tested in outpatient specialty care (AOS) and the value of benefits in PLN million, calls into question the advisability of stopping the sending of personal invitations to cervical screening tests as an activity aimed at cost optimization of the process. Referring to the second argument concerning the ineffectiveness of invitations, it is necessary to cite the studies of independent centers, which say that the use of personalized methods of contact targeted at specific age groups, combined with setting the date of the examination, significantly increases participation in the screening program [12-14]. The increased interest the private healthcare sector has shown in performing screening tests may result, in part, from the availability of improved diagnostic methods, including the possibility of testing for the presence of HPV [15].

The current state of knowledge indicates that almost all CCS are caused or co-caused by persistent high-risk HPV (hrHPV) infection. Two genotypes (16 and 18) are responsible for $70 \%$ of CC and $50 \%$ of HSIL cases [4]. High-risk HPV tests are characterized by a $20-50 \%$ higher sensitivity than routine cervical cytology which means that the risk of overlooking a malignant transformation from precancer to cancer is minimized when compared with a Pap smear slide evaluation (when, in both cases, a negative screening test result is compared) [3].

Our study shows that the declining number of women screened under the national screening program is accompanied by a slight reduction in the national mortality rate from cervical cancer (ASW decreased by 0.64 percentage points over the studied 7-year period). Analysis over a broader time period showed that the annual percentage change (APC 1990-2017) in the mortality rate in Poland accounted -2.3. By comparison, in the countries of the so-called old European Union (EU15), the APC was -2.5, with a low ASW rate of 1.9 [16].

Considering our results and those of other researchers, the slight decrease in mortality observed in Poland should be considered unsatisfactory and indicates the need to make changes in the overall approach of the preventive program. Moreover, the observed decrease in mortality may be partly attributed to the activities of the private healthcare sector in Poland, but we do not have sufficient data to test this hypothesis. We suggest creating a national cervical cancer prevention register that encompasses the combined data of both the NHF and the private sector.

In studies assessing the Standard Expected Years of Life Lost per death (SEYLLd), for every woman's death in Poland from CC in 2011, the SEYLLd was 25.8 years lost, while in 2015 it was 23.7 years. Despite this decrease, when analyzed according to education level, the SEYLLd in women with only primary school education, was 5.8 times greater than in women with higher education [17]. This relationship is another reason to suggest that reintroducing personalized invitations for specific social groups ("Poland says STOP cervical cancer") may be beneficial. Another interesting option especially for young people starting sexual activity can be Instagram influencers spots to encourage vaccination against HPV.

Across the analyzed period, the average annual cost of detecting one lesion requiring further treatment remained at the relatively constant level of 1,467.86 PLN, and the average annual cost of treatments also remained constant at 132.3 
million PLN. This funding level places a heavy burden on the public health system. The large number of women treated for CC and the high costs of prophylaxis and treatment constitute a significant challenge for the healthcare budget in Poland and worldwide as well [18, 19]. Various cost-saving measures undertaken so far, including the inclusion of primary healthcare midwives in the cytology collection process, have not produced the expected results [20]. An effective solution may be the introduction of HPV screening tests [21, 23]. Recent research results suggest that replacing a triennial program of cytology with screening for HPV every 5 years has benefits [24, 25].

The CC mortality rate decreased insignificantly over the period of our study, despite high, though relatively constant, levels of treatment cost. According to OECD data, even though Poland's 5-year survival results (55\%) for CC treatment have improved slightly, they are still below the European average of $63 \%[9,26]$. It should therefore be assumed that if CC treatment in Poland is operating below the average European effectiveness, there is room for improvement.

Apart from the ethical aspect, Poland's relatively low 5-year survival rate of CC has an economic context. In 2012 alone, CC incidence and the consequent mortality caused the loss of approximately 957,678 working days in Poland, and this resulted in production losses of EUR 111.4 million, $66 \%$ of which was related to mortality [27].

Our study has shown that in Poland, public sector CC treatment costs and the duration of hospitalization have both remained at constant levels during our study period. In comparison, Western European countries have seen a decrease in the cost of treatment with accompanying reductions in morbidity and mortality [28]. Those countries are seeing the long-term effects of the introduction of the HPV vaccination, which is not yet common in Poland $[29,30]$. It is worth emphasizing that for the period we analyzed, our study did not identify any significant statistical relationships between the cost of treatment services provided and the mortality rate expressed by ASW. This may suggest a relationship between the decline in mortality and the level of preventive measures only, and not the quality of treatment services. However, in the context of CC, there are no reports in the current literature that would challenge what our study discovered. In the absence of a relationship between the cost of treatment and mortality rates, the hypothesis that mortality rates are influenced by preventative measures rather than by hospital services remains.

\section{Limitations}

This study has several limitations. Actual recommended tools for an analysis of health care systems in the context of cost-effectiveness, including cervical cancer prevention are the Incremental Cost-Effectiveness Ratio (ICER), Quality Adjusted Life Year (QALY), and Quality-Adjusted Life Expectancy (QALE). These parameters were not used in the study due to the lack of current data from Poland in the literature. The results of other scientists refer to years earlier than presented in our study.

\section{Conclusions}

We want to draw attention to the systematic decrease in the number of patients undergoing cytological examinations funded by the state, which also translates into a reduction of the percentage of the population covered. The recommended solution is to return to personalized invitations, but instead of using letters as before, we suggest that invitations be made through "new media" - e-mail/SMS under the administration of a primary care physician and midwife. The results of our research suggest that patients may be undergoing cytological testing in private healthcare settings. This situation significantly impedes public access to complete statistical data and a comprehensive assessment of the effectiveness of cervical cancer preventive measures and resourcing in Poland. To enable a full analysis in the future, we propose the creation of a national cervical screening registry to include all National Health Funded providers and private healthcare sector providers.

The issue that our report raises, regarding the falling number of women undergoing Pap smear testing within public healthcare settings, also results from the difficulty of public healthcare providers accessing modern diagnostic methods such as liquid-based cytology or molecular diagnostics for the presence of HPV; these observations also indicate possible avenues for changes. The slow decrease in mortality due to cervical cancer described in our study can be accelerated by introducing mandatory vaccination against HPV. Currently, the limited spread of mandatory vaccination programs, funded by some municipalities, has not had a noticeable effect on population-wide data. Poland's unsatisfactory 5-year cervical cancer survival rates may be a result of the phenomena described above: declining prophylactic examination rates across the whole population, diagnostics primarily based on cytological smears, and the limited availability of vaccination against HPV.

We believe that the current processes of diagnosis and treatment of cervical cancer in Poland require a change of approach in line with the recommendations presented in our study.

\section{Conflict of interest: none declared}

\section{Patryk Poniewierza \\ Medical University of Gdansk \\ Department of Biology and Medical Genetics \\ ul. Debinki 1 \\ 80-211 Gdańsk, Poland \\ e-mail:patryk.poniewierza@gumed.edu.pl}

Received: 1 Nov 2021

Accepted: 4 Jan 2022

\section{References}

1. Sung H, Ferlay J, Siegel RL, et al. Global Cancer Statistics 2020: GLOBOCAN Estimates of Incidence and Mortality Worldwide for 36 Cancers in 185 Countries. CA Cancer J Clin. 2021; 71(3): 209-249, doi: 10.3322/ caac.21660, indexed in Pubmed: 33538338.

2. Wojciechowska U, Didkowska J, Michałek I. Cancer in Poland in 2018 Polish National Cancer Registry, Warsaw 2020. 
3. Nowakowski A, Arbyn M, Turkot MH, et al. A roadmap for a comprehensive control of cervical cancer in Poland: integration of available solutions into current practice in primary and secondary prevention. Eur $\mathrm{J}$ Cancer Prev. 2020; 29(2): 157-164, doi: 10.1097/CEJ.0000000000000528, indexed in Pubmed: 31517672

4. Nowakowski A, Turkot M, Miłosz K. Should we continue population-based cervical cancer screening programme in Poland? A statement in favour. Nowotwory. Journal of Oncology. 2018; 68(2): 108-112, doi: 10.5603/njo.2018.0017.

5. de Rycke $Y$, Tubach $F$, Lafourcade $A$, et al. Cervical cancer screening coverage, management of squamous intraepithelial lesions and related costs in France. PLoS One. 2020; 15(2): e0228660, doi: 10.1371/journal. pone.0228660, indexed in Pubmed: 32053648

6. Wojciechowska U, Didkowska J. Changes in five-year relative survival rates in Poland in patients diagnosed in the years 1999-2010. Nowotwory. Journal of Oncology. 2018;67(6): 349-358, doi: 10.5603/njo.2017.0057.

7. Sant M, Lopez MC, Agresti R, et al. Survival of women with cancers of breast and genital organs in Europe 1999-2007: Results of the EUROCARE-5 study. European Journal of Cancer. 2015; 51(15): 2191-2205, doi: 10.1016/j.ejca.2015.07.022.

8. Devarapalli P, Labani S, Nagarjuna N, et al. Barriers affecting uptake of cervical cancer screening in low and middle income countries: A systematic review. Indian J Cancer. 2018; 55(4): 318-326, doi: 10.4103/ijc. IJC_253_18, indexed in Pubmed: 30829264.

9. Screening, survival and mortality for cervical cancer. Health at a Glance: Europe. 2018: 158-159, doi: 10.1787/health_glance_eur-2018-41-en.

10. Arbyn $M$, Castellsagué $X$, de Sanjosé $S$, et al. Worldwide burden of cervical cancer in 2008. Ann Oncol. 2011; 22(12): 2675?2686, doi: 10.1093/ annonc/mdr015, indexed in Pubmed: 21471563.

11. Turkot M, Mokwa D, Wieszczy $\mathrm{P}$, et al. External audit of providers of the Cervical Cancer Prevention Programme in Poland in 2016/2017. Nowotwory. Journal of Oncology. 2018; 68(2): 65-78, doi: 10.5603/njo.2018.0011.

12. Bao HL, Wang LH, Wang LM, et al. Zhonghua Liu Xing Bing Xue Za Zhi. 2018; 39(2): 208-212.

13. Acera A, Manresa JM, Rodriguez D, et al. Increasing Cervical Cancer Screening Coverage: A Randomised, Community-Based Clinical Trial. PLoS One. 2017; 12(1): e0170371, doi: 10.1371/journal.pone.0170371, indexed in Pubmed: 28118410.

14. Kurt G, Akyuz A. Evaluating the Effectiveness of Interventions on Increasing Participation in Cervical Cancer Screening. J Nurs Res. 2019; 27(5): e40, doi: 10.1097/jnr.0000000000000317, indexed in Pubmed: 30908429.

15. Koliopoulos G, Nyaga VN, Santesso N, et al. Cytology versus HPV testing for cervical cancer screening in the general population. Cochrane Database Syst Rev. 2017; 8: CD008587, doi: 10.1002/14651858.CD008587. pub2, indexed in Pubmed: 28796882

16. Wojtyla C, Ciebiera M, Kowalczyk D, et al. Cervical Cancer Mortality in East-Central European Countries. Int J Environ Res Public Health. 2020; 17(13), doi: 10.3390/ijerph17134639, indexed in Pubmed: 32605159.

17. Pikala M, Burzyńska M, Maniecka-Bryła I. Years of Life Lost Due to Cervical Cancer in Poland in 2000 to 2015. Int J Environ Res Public Health. 2019; 16(9), doi: 10.3390/ijerph16091545, indexed in Pubmed: 31052396.

18. Nowakowski A, Śliwczyński A, Seroczyński P, et al. Reimbursed Costs of Management of Uterine Cervical Lesions in Poland--a Descriptive
Analysis of Data from the National Health Fund and the Ministry of Health. Cent Eur J Public Health. 2016; 24(2): 163-168, doi: 10.21101/ cejph.a4737, indexed in Pubmed: 27178030.

19. Pendrith C, Thind A, Zaric GS, et al. Costs of cervical cancer treatment: population-based estimates from Ontario. Curr Oncol. 2016; 23(2): e109-e115, doi: 10.3747/co.23.2598, indexed in Pubmed: 27122978.

20. Sobczyk K, Woźniak-Holecka J, Holecki T, et al. The organization and financing of cervical cancer prevention carried out by midwives in primary health care. Ginekol Pol. 2016; 87(12): 798-804, doi: 10.5603/ GP.2016.0091, indexed in Pubmed: 28098929.

21. Mezei AK, Armstrong HL, Pedersen HN, et al. Cost-effectiveness of cervical cancer screening methods in low- and middle-income countries: A systematic review. Int J Cancer. 2017; 141(3): 437-446, doi: 10.1002/ ijc.30695, indexed in Pubmed: 28297074.

22. Campos NG, Maza M, Alfaro $K$, et al. The cost-effectiveness of implementing HPV testing for cervical cancer screening in El Salvador. Int J Gynaecol Obstet. 2019; 145(1): 40-46, doi: 10.1002/ijgo.12773, indexed in Pubmed: 30702142.

23. Pista A, Costa C, Saldanha C, et al. Budget impact analysis of cervical cancer screening in Portugal: comparison of cytology and primary HPV screening strategies. BMC Public Health. 2019; 19(1): 235, doi: 10.1186/ s12889-019-6536-4, indexed in Pubmed: 30808324.

24. Diaz $M$, Moriña $D$, Rodríguez-Salés $V$, et al. Moving towards an organized cervical cancer screening: costs and impact. Eur J Public Health. 2018; 28(6): 1132]1138, doi: 10.1093/eurpub/cky061, indexed in Pubmed: 29684144.

25. Sawaya GF, Sanstead E, Alarid-Escudero F, et al. Estimated Quality of Life and Economic Outcomes Associated With 12 Cervical Cancer Screening Strategies: A Cost-effectiveness Analysis. JAMA Intern Med. 2019; 179(7): 867-878, doi: 10.1001/jamainternmed.2019.0299, indexed in Pubmed: 31081851.

26. Gliniewicz A, Zielińska A, Kwiatkowska K, et al. Survival in women diagnosed with breast and cervical cancer in Poland - compared to European countries, based on CONCORD - 3 Programme. Przegl Epidemiol. 2018; 72(4): 499-508, doi: 10.32394/pe.72.4.25, indexed in Pubmed: 30810005.

27. Dubas-Jakóbczyk K, Kocot E, Seweryn M, et al. Production lost due to cervical cancer in Poland in 2012. Med Pr. 2016; 67(3): 289]299, doi: 10.13075/mp.5893.00378, indexed in Pubmed: 27364103.

28. Bianchi FP, Gallone MS, Fortunato F, et al. Epidemiology and cost of cervical cancer care and prevention in Apulia (Italy), 2007/2016. Ann Ig. 2018; 30(6): 490-501, doi: 10.7416/ai.2018.2249, indexed in Pubmed: 30614498.

29. Chesson HW, Meites E, Ekwueme DU, et al. Updated medical care cost estimates for HPV-associated cancers: implications for cost-effectiveness analyses of HPV vaccination in the United States. Hum Vaccin Immunother. 2019; 15(7-8): 1942-1948, doi: 10.1080/21645515.2019.1603562, indexed in Pubmed: 31107640.

30. Wolff E, Elfström KM, Haugen Cange $H$, et al. Cost-effectiveness of sex-neutral HPV-vaccination in Sweden, accounting for herd-immunity and sexual behaviour. Vaccine. 2018; 36(34): 5160?5165, doi: 10.1016/j. vaccine.2018.07.018, indexed in Pubmed: 30017146 